\title{
Cogestão e saúde mental: revisão integrativa sobre os saberes e práticas compartilhadas na rede de saúde
}

Co-management and mental health: integrative review on knowledge and shared practices in the health network

Cogestión y salud mental: revisión integradora del conocimiento y las prácticas compartidas en la red de salud

Recebido: 30/09/2021 | Revisado: 06/10/2021 | Aceito: 06/10/2021 | Publicado: 10/10/2021

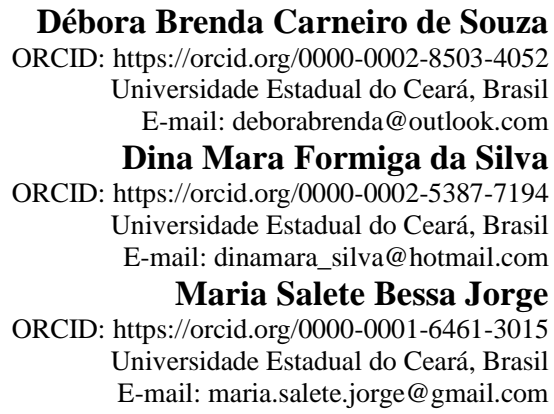

\begin{abstract}
Resumo
Objetivo: compreender os processos de cogestão, os saberes e as práticas compartilhadas entre profissionais de saúde e usuários e sua interface com a saúde mental na rede. Metodologia: Revisão Integrativa da literatura, que tem como base as seis fases estabelecidas por Mendes, Silveira e Galvão, sendo utilizada a estratégia PCC para a formulação da pergunta norteadora, e busca detalhada e individual realizada na Scielo, Pubmed e Literatura Latino-Americana e do Caribe em Ciências da Saúde (LILACS) via Biblioteca Virtual em Saúde (BVS) em agosto de 2021. Resultados: Foram selecionados 13 artigos para análise e elaboração da matriz de síntese. Discussão: Ao abordar os modelos de gestão compartilhada dos serviços de saúde, tem-se que considerar os limites de qualquer reforma gerencial ou do modelo de gestão; o que se pode apreender com base nos artigos analisados, é que para tal, é preciso considerar os mais diversos variados e completos fatores, estando entre eles, o contexto econômico, político, social e cultural. Conclusão: é necessário que haja um esforço dos profissionais de saúde e dos gestores em promover a cogestão de forma plena, passando a considerar os usuários como peça fundamental para que ela seja executada, visando a construção de espaço que fomentem discussões sobre o cuidado em saúde mental de modo compartilhado por todos os atores sociais.
\end{abstract}

Palavras-chave: Cogestão; Saúde mental; Gestão em saúde.

\begin{abstract}
Objective: to understand the processes of co-management, knowledge and practices shared between health professionals and users and their interface with mental health in the network. Methodology: Integrative literature review, which is based on the six phases established by Mendes, Silveira and Galvão, using the PCC strategy for the formulation of the guide question, and detailed and individual search conducted in Scielo, Pubmed and Latin American and Caribbean Literature in Health Sciences (LILACS) via the Virtual Health Library (VHL) in August 2021. Results: 13 articles were selected for analysis and elaboration of the synthesis matrix. Discussion: When addressing the shared management models of health services, one has to consider the limits of any management reform or management model; what can be apprehended based on the articles analyzed, is that for this, it is necessary to consider the most varied and complete factors, being among them, the economic, political, social and cultural context. Conclusion: it is necessary that there is an effort of health professionals and managers to promote comanagement in a full way, starting to consider users as a fundamental part for it to be executed, aiming at the construction of space that foster discussions about mental health care in a way shared by all social actors.
\end{abstract}

Keywords: Co-management; Mental health; Health management.

\section{Resumen}

Objetivo: comprender los procesos de cogestión, conocimientos y prácticas compartidas entre los profesionales de la salud y los usuarios y su interfaz con la salud mental en la red. Metodología: Revisión integradora de la literatura, que 
se basa en las seis fases establecidas por Mendes, Silveira y Galvão, utilizando la estrategia PCC para la formulación de la pregunta guía, y búsqueda detallada e individual realizada en Scielo, Pubmed y Literatura Latinoamericana y del Caribe en Ciencias de la Salud (LILACS) a través de la Biblioteca Virtual en Salud (BVS) en agosto de 2021. Resultados: Se seleccionaron 13 artículos para el análisis y elaboración de la matriz de síntesis. Discusión: Al abordar los modelos de gestión compartida de los servicios de salud, hay que considerar los límites de cualquier reforma de gestión o modelo de gestión; lo que se puede aprehender en base a los artículos analizados, es que para ello, es necesario considerar los factores más variados y completos, estando entre ellos, el contexto económico, político, social y cultural. Conclusión: es necesario que exista un esfuerzo de los profesionales y gestores de la salud para promover la cogestión de manera integral, comenzando a considerar a los usuarios como parte fundamental para que se ejecute, apuntando a la construcción de espacios que fomenten discusiones sobre el cuidado de la salud mental de manera compartida por todos los actores sociales.

Palabras clave: Cogestión; Salud mental; Gestión de la salud.

\section{Introdução}

O panorama da Saúde Mental no Brasil é um campo que vem se construindo através dos anos, com diversas formas de expressão, de modo que, encontraremos as mais diversificadas visões sobre o sujeito, sendo ele um desviante das normas da sociedade, um louco que precisa ser mantido afastado ou um ser em sua totalidade que precisa ser compreendido em sua forma biopsicossocial (Amarante, 1996; Sampaio et al., 2011).

As políticas de saúde mental no Brasil foram conquistadas a partir do processo da reforma psiquiátrica, uma luta pela afirmação da cidadania do louco, uma busca em tentar proporcionar à loucura uma resposta social diferente, ou seja, proporcionar ao louco um lugar social de fato (Tenório, 2002; Pinto et al, 2012).

Desse modo, o processo da reforma psiquiátrica possibilitou ao louco, pessoa excluída da sociedade e destituída do seu poder social, lugar de cidadão e sujeito de direitos, de forma que esses indivíduos passaram a ocupar-se de sua condição de ser e de estar em sociedade.

Concomitante ao processo da reforma psiquiátrica, temos a reforma sanitária no Brasil, que traz com ela, grandes marcos, como a $8^{\text {a }}$ Conferência Nacional, que fomentou documentos que norteariam a criação da Constituição Federal de 1988 , que apresentava em seu caráter essencial, propostas advindas dessas discussões e da ampliação da compreensão do conceito de saúde e da participação da comunidade nos processos de saúde (Cunha \& Cunha, 1998; Escorel, 2015).

É em sua concepção política e ideológica que a Reforma Sanitária “defendia a saúde não como uma questão exclusivamente biológica a ser resolvida pelos serviços médicos, mas sim como uma questão social e política a ser abordada no espaço público" (Paim et al., 2011, p.18).

Destarte, a população passou a ser reconhecida em seu pleno poder, assumindo assim, papel importante, juntamente com os profissionais da saúde e da gestão, de corresponsável por sua situação de saúde. Esse modo de inclusão de novos sujeitos nos processos de gestão é conhecido como gestão compartilhada ou cogestão, termo forjado por Campos (2000) que aborda aspectos de uma gestão compartilhada entre os diversos atores sociais e traz a importância desse projeto para a produção e construção do sujeito, dando-o maior liberdade, capacidade reflexiva e autonomia, pilares fundamentais quando falamos desse sujeito que se constitui enquanto usuário dos serviços de saúde mental.

Posto isto, têm-se como objetivo compreender os processos de cogestão, os saberes e as práticas compartilhadas entre profissionais de saúde e usuários e sua interface com a saúde mental na rede.

\section{Metodologia}

Trata-se de uma revisão integrativa, cuja abordagem utilizada é do tipo qualitativa. A revisão integrativa inclui a análise de pesquisas relevantes que dão suporte para a tomada de decisão e a melhoria da prática clínica, possibilitando a 
síntese do estado do conhecimento de um determinado assunto, além de apontar lacunas do conhecimento que precisam ser preenchidas com a realização de novos estudos (Mendes et al, 2008).

Para a formulação da questão norteadora do estudo utilizamos a pergunta PCC, a estratégia PICO adaptada. Na adaptação, tais mnemônicos significa P- população, C- conceito e C- contexto/desfecho. Assim, a estratégia foi formulada da seguinte maneira: P- profissionais e usuários; C- cogestão e saúde mental; C- rede de atenção psicossocial (Peters et al. 2015).

Desta forma, estabeleceu-se, a seguinte questão: como ocorre processos de cogestão, os saberes e as práticas compartilhadas entre profissionais de saúde e usuários e sua interface com a saúde mental na rede?

Após identificação dos Descritores em Ciências da Saúde (DeCS), foi realizada uma estratégia de busca detalhada e individual na Scientific Electronic Library Online (SCIELO), National Library of Medicine (PUBMED) e Literatura LatinoAmericana e do Caribe em Ciências da Saúde (LILACS) via Biblioteca Virtual em Saúde (BVS).

Foram extraídos para uso três descritores do DeCS, sendo eles "Gestão em saúde", "saúde mental", e uma palavrachave "cogestão" a qual apresenta grande significância para o estudo. Quanto à estratégia de busca, foram elencados os seguintes critérios de inclusão: artigos completos disponíveis na íntegra dos últimos dez anos, no idioma português que apresentassem pelo menos um dos descritores estabelecidos. Foram excluídas as publicações que estivessem relacionadas com pelo menos um dos critérios: 1) revisões, 2) carta ao editor, 3) opinião pessoal dos autores, 4) resumos de encontros, 5) vídeos, 6) ausência de dados que apresentam relação com o objeto de estudo.

Os artigos selecionados foram listados, organizados e analisados em um quadro síntese, analisando informações especificas de cada artigo relacionados à autoria, ano de publicação, título, base de dados, objetivo e resultados. Tendo em vista, compreender o conceito, aplicabilidade, possibilidades no contexto da saúde.

Nesta fase apresentamos as discussões dos principais resultados de cada artigo. A autora empreendeu uma análise crítica dos artigos, do referencial teórico e reproduziu questões inerentes à revisão integrativa, contudo podendo direcionar estudos futuros e gerando novos conhecimentos sobre a real importância do estudo.

O software Endnotweb foi utilizado para a organização de todas as referências e a remoção dos artigos duplicados. Para a análise dos dados, foi utilizada a Análise de Conteúdo de Bardin (2011).

\section{Resultados}

A busca inicial teve a seguinte distribuição entre as publicações encontradas: Scielo ( $n=142)$, Lilacs ( $n=136)$, Pubmed $(n=149)$, totalizando (427) publicações. Em seguida, foram aplicados os filtros, destes foram excluídos (n=311) após lido os títulos, restando $(\mathrm{n}=116)$ para serem lidos os resumos. Assim, restaram $(\mathrm{n}=126)$ para serem analisados, contudo destes (n=113) não se encaixaram.

Quadro 1 - Resultados da busca nas bases de dados e seleção de artigos.

\begin{tabular}{|l|c|c|c|c|c|c|}
\hline $\begin{array}{c}\text { BASE DE } \\
\text { DADOS }\end{array}$ & \multicolumn{2}{|c|}{ TÍTULOS } & \multicolumn{2}{c|}{ RESUMOS } & \multicolumn{2}{c|}{ ARTIGOS } \\
\hline & TOTAL & ACEITOS & TOTAL & ACEITOS & TOTAL & ACEITOS \\
\hline Scielo & 142 & 38 & 38 & 17 & 17 & 3 \\
\hline Lilacs & 136 & 42 & 42 & 11 & 11 & 4 \\
\hline Pubmed & 149 & 36 & 36 & 7 & 7 & 6 \\
\hline TOTAL & 427 & 116 & 116 & 35 & 35 & 13 \\
\hline
\end{tabular}

Fonte: Autores (2021). 
Sendo assim, restaram ( $\mathrm{n=13}$ ) para análise e elaboração da matriz de síntese (Quadro 2). Os dados da presente revisão possibilitaram uma maior exploração do tema com vistas à ampliação de conhecimentos acerca da cogestão, entendendo que esse conceito implica em uma gestão exercida em comum por duas ou mais pessoas; administração ou gerência em sociedade. Infere-se que nesse estudo relaciona-se o conceito de cogestão com o contexto da saúde, especificamente relacionado ao Sistema de Saúde Pública - SUS.

Quadro 2 - Caracterização dos estudos incluídos na Revisão Integrativa.

\begin{tabular}{|c|c|c|c|}
\hline Titulo & $\begin{array}{l}\text { Autores/ } \\
\text { Ano }\end{array}$ & $\begin{array}{l}\text { Periódico/ Base de } \\
\text { Dados }\end{array}$ & Objetivo \\
\hline $\begin{array}{l}\text { O conceito de cogestão em saúde: } \\
\text { reflexões sobre a produção de } \\
\text { democracia institucional }\end{array}$ & $\begin{array}{l}\text { GUIZARDI, F. L.; } \\
\text { CAVALCANTI, F. O. } \\
\text { L. / } 2010 .\end{array}$ & $\begin{array}{l}\text { Physis Revista de } \\
\text { Saúde Coletiva./ } \\
\text { Pubmed. }\end{array}$ & $\begin{array}{l}\text { Discutir os elementos necessários à } \\
\text { composição do conceito de cogestão, tendo } \\
\text { por perspectiva a necessidade de repensar os } \\
\text { modos de gestão do Sistema Único de Saúde }\end{array}$ \\
\hline $\begin{array}{l}\text { Cogestão e processo de intervenção } \\
\text { de apoiadores da Política Nacional } \\
\text { de Humanização (PNH) }\end{array}$ & $\begin{array}{l}\text { CALDERON, D. B. L.; } \\
\text { VERDI, M. I. M. / } \\
2014 .\end{array}$ & $\begin{array}{l}\text { Interface. } \\
\text { Comunicação, saúde } \\
\text { educação./ Scielo. }\end{array}$ & $\begin{array}{l}\text { Analisar as mudanças nos modos de gestão } \\
\text { geradas pelo processo de intervenção dos } \\
\text { apoiadores institucionais formados no Curso } \\
\text { de Apoiadores Institucionais para a } \\
\text { Humanização da Atenção e Gestão do } \\
\text { Sistema Único de Saúde (SUS) em 2009, em } \\
\text { Santa Catarina, Brasil }\end{array}$ \\
\hline $\begin{array}{l}\text { Cogestão e neoartesanato: } \\
\text { elementos conceituais para repensar } \\
\text { o trabalho em saúde combinando } \\
\text { responsabilidade e autonomia }\end{array}$ & $\begin{array}{l}\text { CAMPOS, G. W. S./ } \\
2010\end{array}$ & $\begin{array}{l}\text { Ciência \& Saúde } \\
\text { Coletiva./Lilacs }\end{array}$ & $\begin{array}{l}\text { Discute tensões entre a racionalidade } \\
\text { gerencial dominante e o trabalho em saúde. }\end{array}$ \\
\hline $\begin{array}{l}\text { Apoio institucional e cogestão: a } \\
\text { experiência da Política Nacional de } \\
\text { Humanização no Sistema Único de } \\
\text { Saúde (SUS) no Distrito Federal, } \\
\text { Brasil }\end{array}$ & $\begin{array}{l}\text { MORI, M. E.; } \\
\text { OLIVEIRA, O. V. M. / } \\
2014 .\end{array}$ & $\begin{array}{l}\text { Interface. } \\
\text { Comunicação, saúde } \\
\text { educação./ Scielo. }\end{array}$ & $\begin{array}{l}\text { A intervenção objetivou mudanças nos } \\
\text { modelos de atenção e gestão e, } \\
\text { consequentemente, fortalecimento da Rede } \\
\text { SUS no DF. }\end{array}$ \\
\hline $\begin{array}{l}\text { Educação permanente e cogestão: } \\
\text { experiência de um grupo gestor em } \\
\text { saúde }\end{array}$ & $\begin{array}{l}\text { COSTA, D. F. C; } \\
\text { FLORES, M. G. C; } \\
\text { ANDREETI, T. O. } \\
2015 .\end{array}$ & $\begin{array}{l}\text { Estudos } \\
\text { Interdisciplinares em } \\
\text { Psicologia. / BVS. }\end{array}$ & $\begin{array}{l}\text { Apresenta uma experiência de reorganização } \\
\text { do processo de trabalho no intuito de } \\
\text { enfrentar a histórica fragmentação das ações } \\
\text { no campo da gestão em saúde. }\end{array}$ \\
\hline $\begin{array}{l}\text { Relações entre pesquisa e clínica em } \\
\text { estudos em cogestão com usuários } \\
\text { de saúde mental }\end{array}$ & $\begin{array}{l}\text { PALOMBINI, A. L. et } \\
\text { al. } / 2013\end{array}$ & $\begin{array}{l}\text { Ciência \& Saúde } \\
\text { Coletiva./Lilacs }\end{array}$ & $\begin{array}{l}\text { Propõe-se a cogestão como estratégia a partir } \\
\text { da qual os diferentes atores implicados na } \\
\text { condução da pesquisa e no exercício da } \\
\text { clínica }\end{array}$ \\
\hline $\begin{array}{l}\text { O apoio institucional no Sistema } \\
\text { Único de Saúde (SUS): os dilemas } \\
\text { da integração interfederativa e da } \\
\text { cogestão }\end{array}$ & $\begin{array}{l}\text { PEREIRA JÚNIOR, } \\
\text { N.; CAMPOS, G. W. } \\
\text { S. / } 2014 .\end{array}$ & $\begin{array}{l}\text { Interface. } \\
\text { Comunicação, saúde } \\
\text { educação./ Scielo. }\end{array}$ & $\begin{array}{l}\text { Compreender a formulação do apoio } \\
\text { institucional pelo Ministério da Saúde (MS) e } \\
\text { como essa estratégia do método da roda vem } \\
\text { sendo incorporada ao discurso oficial da } \\
\text { gestão federal do SUS. }\end{array}$ \\
\hline $\begin{array}{l}\text { Entre "feudos" e cogestão: } \\
\text { paradoxos da autonomia em uma } \\
\text { experiência de democratização da } \\
\text { gestão no âmbito hospitalar }\end{array}$ & $\begin{array}{l}\text { SILVA, A.M.; SÁ, M. } \\
\text { C.; MIRANDA, L. / } \\
2015 .\end{array}$ & $\begin{array}{l}\text { Ciência \& Saúde } \\
\text { Coletiva./Lilacs }\end{array}$ & $\begin{array}{l}\text { Analisar a implantação dos Colegiados } \\
\text { Gestores (CGs) e Unidades de Produção } \\
\text { (UPs) em um hospital do Rio de Janeiro, na } \\
\text { perspectiva do discurso dos atores } \\
\text { responsáveis por esse processo, focalizando a } \\
\text { problemática da autonomia dos sujeitos } \\
\text { implicados na produção do cuidado. }\end{array}$ \\
\hline $\begin{array}{l}\text { O Compartilhamento do Cuidado } \\
\text { em Saúde Mental: uma experiência }\end{array}$ & $\begin{array}{l}\text { GODOY, M. G. C. et } \\
\text { al. / } 2012\end{array}$ & Saúde Soc. / Pubmed & $\begin{array}{l}\text { Apresentamos a trajetória histórica da referida } \\
\text { entidade, descrevemos algumas de suas }\end{array}$ \\
\hline
\end{tabular}




\begin{tabular}{|c|c|c|c|}
\hline $\begin{array}{l}\text { de cogestão de um centro de atenção } \\
\text { psicossocial em Fortaleza, CE, } \\
\text { apoiada em abordagens } \\
\text { psicossociais }\end{array}$ & & & $\begin{array}{l}\text { principais atividades e realizamos uma breve } \\
\text { análise da parceria com a Secretaria } \\
\text { Municipal de Saúde e o processo de cogestão } \\
\text { do Centro de Atenção Psicossocial, }\end{array}$ \\
\hline $\begin{array}{l}\text { Aspectos contextuais na construção } \\
\text { da cogestão em Unidades Básicas de } \\
\text { Saúde }\end{array}$ & $\begin{array}{l}\text { GUANAES- } \\
\text { LORENZI, C.; } \\
\text { DORICCI, G. C. } / 2020\end{array}$ & $\begin{array}{l}\text { Saúde Debate / } \\
\text { Pubmed }\end{array}$ & $\begin{array}{l}\text { Descrever e compreender como aspectos } \\
\text { contextuais favorecem ou limitam a } \\
\text { construção da cogestão no âmbito da Atenção } \\
\text { Básica }\end{array}$ \\
\hline $\begin{array}{l}\text { Autonomia e cogestão na prática em } \\
\text { saúde mental: o dispositivo da } \\
\text { gestão autônoma da medicação } \\
\text { (GAM) }\end{array}$ & $\begin{array}{l}\text { PASSOS, E. et al. } \\
/ 2010 .\end{array}$ & Aletheia. / BVS & $\begin{array}{l}\text { Objetivou a elaboração do Guia Brasileiro da } \\
\text { Gestão Autônoma da Medicação (Guia GAM- } \\
\text { BR), com base na tradução e adaptação do } \\
\text { Guia GAM desenvolvido no Quebec - } \\
\text { instrumento dirigido a pessoas com } \\
\text { transtornos mentais graves. }\end{array}$ \\
\hline $\begin{array}{l}\text { Apoio Matricial no SUS Campinas: } \\
\text { análise da consolidação de uma } \\
\text { prática interprofissional na rede de } \\
\text { saúde }\end{array}$ & $\begin{array}{l}\text { CASTRO, C. P. ; } \\
\text { OLIVEIRA, M, M.; } \\
\text { CAMPOS, G. W. S. / } \\
2015 .\end{array}$ & $\begin{array}{l}\text { Ciência \& Saúde } \\
\text { Coletiva./Lilacs }\end{array}$ & $\begin{array}{l}\text { Caracterizar as equipes e o processo de } \\
\text { trabalho interprofissional do Apoio Matricial } \\
\text { desenvolvido na Atenção Básica do SUS de } \\
\text { Campinas (SP). }\end{array}$ \\
\hline $\begin{array}{l}\text { A cogestão e a inclusão na formação } \\
\text { de apoiadores da Política Nacional } \\
\text { de Humanização nos territórios do } \\
\text { Rio Grande do Sul, Santa Catarina e } \\
\text { São Paulo }\end{array}$ & $\begin{array}{l}\text { VERDI, M. I. M. et al. } \\
\text { / } 2014 .\end{array}$ & $\begin{array}{l}\text { Sau. \& Transf. Soc. / } \\
\text { BVS. }\end{array}$ & $\begin{array}{l}\text { Visa mostrar uma análise acerca da temática } \\
\text { da "Cogestão" e "Inclusão" em três cursos de } \\
\text { formação para apoiadores da Política } \\
\text { Nacional de Humanização da Atenção e } \\
\text { Gestão do SUS (PNH), }\end{array}$ \\
\hline
\end{tabular}

Fonte: Autores (2021).

\section{Discussão}

Discussões sobre os modos de gestão tem-se mostrado sempre presente nas reflexões acadêmicas quando o assunto se estende por uma lógica administrativa, porém, a partir da década de 1980, é visto um destaque para a gestão participativa quando se é abordado o assunto na área da saúde. O termo cogestão, forjado por Campos (2000) foi disposto em diversos artigos e livros, inclusive, na Política Nacional de Humanização (Ministério da Saúde, 2013) que aborda dispositivos que favoreçam ações de humanização tanto na atenção, como na gestão da saúde no Brasil, sendo a cogestão, uma diretriz que orienta melhores arranjos de trabalho.

Para compreender melhor sobre a cogestão é preciso apreender sobre a gestão em saúde como um todo, sendo necessário retroceder um pouco e pensar nas problematizações acerca do assunto. Guizardi e Cavalcanti (2010) trazem exatamente esse ponto em seu texto, ao questionarem sobre como a gestão em saúde acaba, muitas vezes, por atualizar as práticas que vem da tradição da administração moderna, que se foca em necessidades específicas de uma produção voltada apenas para o desenvolvimento do capitalismo, sem pensar nas questões subjetivas dos trabalhadores.

Sendo assim, os autores trazem a importância da construção de espaços que tragam questionamentos e possibilidades de organização pautados em produção de autonomia e liberdade ao invés de espaços que reproduzam uma lógica apenas exploratória e de controle (Guizardi \& Cavalcanti, 2010). Nesse sentido, trata-se de incorporar o subjetivo dos trabalhadores na gestão dos processos de trabalho, considerando seus desejos e atos individuais que caracterizem sua autonomia, sem que isto signifique desconsiderar o diálogo com as necessidades sociais que emergem na sociedade e as questões da empresa.

Norteados por esse entendimento, Guizardi e Cavalcanti (2010) vão além e sinalizam que a gestão em saúde em sua produção de saúde em processos de cogestão "requisita o exercício de capacidades normativas, inclusive no que tange à configuração institucional das alternativas de intervenção". 
Corroborando com esse pensamento, Campos (2010, p. 2342) traz a proposta de reinvenção das instituições de saúde, que se constituiria por "reinventar nelas as maneiras de organização do trabalho, objetivo que confronta os sujeitos à necessidade de analisar e compartilhar as situações que enfrentam, construindo, em função delas, a corresponsabilidade com a formalização de compromissos coletivos". De modo que se constituiria assim, uma democratização institucional como forma estratégica de enfrentamento a uma gerência hegemônica, passando a ser exposto os diferentes agentes sociais do processo de produção de saúde, possibilitando a negociação dos desejos e interesses de ambas as partes (Campos, 2010).

Para pôr em prática essa democratização institucional, o autor, portanto, propõe um método da roda para pensar a gestão de coletivos organizados para a produção. Para tanto faz isso baseado em sua experiência como dirigente e analista de instituições de saúde e ressalta que Bion, Tosquelles e Basaglia foram alguns dos que mostraram o caráter terapêutico do envolvimento de doentes mentais com a gestão cotidiana de suas vidas (Campos, 2010). Para isso, é preciso considerar a cogestão em seus efeitos estratégicos, ou seja, uma ação mútua de afetação, ao mesmo tempo que se concede ao Estado essa forma de gestão, força-se ao Estado a conceder.

Não se trata de um recuo em relação à aposta da autogestão, mas um modo diferente de posiciona-se estrategicamente. Esta passagem de "uma autonomia de vocação autogestionária para uma autonomia cogestiva - não mais exterior ao aparelho de Estado, mas podendo exercer-se por dentro dele - parece-nos uma temática central na discussão dos processos de gestão dos serviços públicos de saúde" (Passos et al, 2013, p. 23). De modo que é possível compreender que a autonomia se caracterizaria por um impulsionamento da cogestão, trazendo os sujeitos que compõe esses serviços como parte do próprio aparelho do Estado e não algo externo a ele.

Já Calderon e Verdi (2014) pontuam a questão da humanização, que deve ser entendida como estratégia de interferência nas práticas de saúde, tendo em sua metodologia o apoio institucional como sua principal estratégia de mobilização de diferentes atores (gestores, trabalhadores e usuários) em torno da tarefa de construção de projetos cogeridos que atendam às necessidades dos diferentes grupos de interesse. Para a concretização do processo de cogestão se faz preciso a interação, sintonia e parceria entre todos os atores que fazem e constroem a gestão em saúde, onde todos os atores envolvidos devem dialogar e contribuir com suas expertises nesse processo.

Corroborando com essa perspectiva Mori e Oliveira (2014) assinalam que a cogestão possibilita uma análise de contexto e problemas do local e fomento de processo de tomada de decisão, sendo tudo isso, exercido por um coletivo de sujeitos que compõem a organização, assumindo que todos são responsáveis por seus processos de trabalho. Esta outra forma de gestão coletiva, advinda de pactos entre os sujeitos, e não exigências sobre eles, traz para a produção de saúde a implicação e a corresponsabilidade pelo cuidado.

Outro ponto que ressalta a implantação da cogestão nos serviços de saúde é a ferramenta da Educação Permanente em Saúde (EPS) entendida por Costa, Flores e Andreeti (2015) como uma estratégia capaz de estimular processos de transformações nos contextos e relações institucionais. Pois, os autores entendem que para que o processo de cogestão possa se efetivar se faz necessário uma postura proativa de educação continuada e permanente dos atores envolvidos nesse processo de modo a sempre alinhar a forma de trabalho as novas possibilidades e tecnologias disponíveis relativas ao seu fazer e em se tratando de saúde tais fatores são primordiais e necessários a práxis cotidiana (Costa et al., 2015).

Vale destacar também o conceito de apoio institucional e sua pertinência para a gestão em saúde, visto a função gerencial que implica entre outros aspetos em mudanças e formas de possibilidades de gestão. Conforme Pereira e Campos (2014) o apoio institucional

[...] se concretiza num modo inovador de se fazer coordenação, planejamento, supervisão e avaliação em saúde, com o objetivo de fomentar e acompanhar processos de mudança nas organizações, ressignificando e articulando conceitos e tecnologias advindas da análise institucional e da gestão. Ofertar suporte aos movimentos de mudança deflagrados por 
coletivos, buscando fortalecê-los no próprio exercício da produção de novos sujeitos em processos de mudança é tarefa primordial do apoio. As diretrizes do apoio institucional integrado são a democracia institucional e a autonomia dos sujeitos, aproveitando as lacunas para ativar movimentos que produzam diferença/ruptura com o que está instituído, ou seja, que busque novos modos de produção da atenção e da gestão na saúde e maior implicação e satisfação dos trabalhadores com seu próprio trabalho (Pereira \& Campos, 2014, p 903).

A partir das colocações feitas pelos autores pode-se afirmar que o método de cogestão implica no amparo a concepção e execução da gestão, sem perder de vista aspectos relacionados a gestão, tais como definição de papéis e atribuições. Sempre focados na mediação, negociação, manejo e aplicação de ferramentas e instrumentos de gestão, perpassando pelo planejamento, avaliação e monitoramento da gestão, visando sempre todos os atores sociais envolvidos nos serviços.

Sobre a relevância de todos os atores sociais envolvidos nos serviços de saúde, observar-se, a partir da análise de Silva, Sá e Miranda (2015) que a inserção dos trabalhadores de saúde em colegiados gestores em um hospital do município da cidade do Rio de Janeiro, no Brasil, proporcionou uma implicação da produção de cuidado, mostrando através dos discursos analisados a valorização desse modo de gestão, pois foi uma forma de ampliar o comprometimento com o serviço, o poder de decisão desses trabalhadores e o compromisso com o cuidado prestado ao usuário. O que se apreende dessa experiência é que proporcionar espaços de reflexão do serviço traz benefícios tanto para a prática profissional, como também fomenta uma produção do cuidado mais engajada e congruente para os usuários do serviço.

A partir da análise feita pelos autores desse artigo, foi possível compreender a importância dos trabalhadores da saúde como um ator de extrema importância para pensar-se em gestão compartilhada, porém, o que deve ser ressaltado é que a cogestão não funciona sem um terceiro ator, o usuário do serviço. Fala-se da melhoria do cuidado ao acrescentar o trabalhar na gestão, mas esquece-se do principal sujeito, o alvo do cuidado, o usuário. Quando questionado sobre a possibilidade de inclusão desses sujeitos, pelos pesquisadores do artigo, os entrevistados colocam-se em posição de reconhecimento da importância da admissão desses sujeitos no desenvolvimento da gestão, mas que é algo a ser pensado para a posterioridade, pois colocá-los no colegiado sem a devida organização só trariam "ruídos desnecessários" (da Silva et al., 2015).

Esse discurso, que ressalta a importância dos usuários do serviço na gestão, mas a ausência deles dentro desses espaços, faz com que questionamentos sejam levantados, por que a voz dos usuários pode ser entendida como ruído desnecessário? Será que esses usuários são realmente vistos como peça fundamental da gestão? Ou apenas atores que trariam mais demandas a um serviço que já se encontra com dificuldades em solucionar suas questões internas? São questionamentos que precisam ser avaliados conforme cada serviço de saúde.

Objetivando dar visibilidade ao usuário dos serviços de saúde e o fomento a autonomia desses sujeitos, Passos et al (2010) realiza um estudo multicêntrico tendo em vista elaboração de um Guia Brasileiro da Gestão Autônoma da Medicação (Guia GAM-BR), com base na tradução e adaptação do Guia GAM desenvolvido no Quebec - instrumento dirigido a pessoas com transtornos mentais graves. A pesquisa acabou assumindo como desafio a implementação dessa ferramenta como exercício de autonomia, protagonismo e exercício de direitos dos usuários nas instituições de saúde mental, tornando-se assim, uma ferramenta capaz de promover a cogestão nesses espaços de saúde, já que através desse dispositivo foi possível agregar o usuário ao modo de produção de cuidado, reconhecendo-o como um ator de produção de saúde.

Voltando as estratégias que favoreçam a cogestão, Castro, Oliveira e Campos (2015) abordam o Apoio Matricial, como ferramenta para o trabalho interprofissional e em rede, que traz o diálogo como centro dessa perspectiva compartilhada de saberes e práticas de saúde, ampliando assim o desenvolvimento de ações que possibilitem a troca entre os profissionais da saúde, a gestão e os usuários, de modo a garantir espaços de reflexão e avaliação das ações desenvolvidas.

A partir desse estudo os autores supracitados destacam a necessidade de compreender a possibilidade de manutenção da cultura de realização do Apoio Matricial, sendo, portanto, importante verificar a existência de avaliação das 
ações desenvolvidas e de espaços regulares de supervisão clínico-institucional desses profissionais, que serviriam como dispositivos de divulgação dos pressupostos inerentes à referida metodologia de trabalho. Doravante é salutar "a importância de criação de formas de avaliação das atividades de maneira participativa, com base na cogestão, para se avançar na consolidação do Apoio Matricial” (de Castro et al., 2016, p.1633-34).

Acrescentando sobre cogestão em espaços públicos de saúde, Doricci e Guanales-Lorenzi (2020, p. 1053) trazem em seu artigo a descrição e compreensão dos aspectos contextuais que podem favorecer ou limitar a construção da cogestão no âmbito da Atenção Básica. Sendo algum dos resultados, os aspectos contextuais “(...), horário de funcionamento, equipe multiprofissional e necessidade de reuniões, formação do médico, agentes comunitários, e organização do espaço físico como facilitadores para o funcionamento em cogestão". Desse modo, vale ressaltar que "a cogestão de coletivos organizados para a produção depende de vontade política e de condições objetivas. A proposta é trabalhar sujeitos e instituições. Um movimento interferindo e modificando o outro" (Doricci \& Guanaes-Lorenzi, 2020, p.1062). Sua efetivação só é possível quando ocorre o comprometimento e entendimento dos aspectos micro e macros relacionados a essa nova forma de gerir a saúde.

Em suma, a partir da análise dos estudos aqui apresentados compete esclarecer que a discussão acerca da gestão em saúde e cogestão é de extrema importância, principalmente por aqueles que fazem a defesa do nosso sistema de saúde e que estão interessados em seu avanço, com qualidade e equidade. Ao abordar os modelos de gestão compartilhada dos serviços de saúde, temos que considerar os limites de qualquer reforma gerencial ou do modelo de gestão; o que se pode apreender com base nos artigos analisados, é que para tal, é preciso considerar os mais diversos variados e completos fatores, estando entre eles, o contexto econômico, político, social e cultural (Calderon \& Verdi, 2014; Campos, 2010).

\section{Considerações Finais}

Esse artigo reuniu conhecimento acerca da gestão em saúde, cogestão e saúde mental, sendo destacado as perspectivas, práticas e saberes compartilhados sobre cogestão nos serviços de saúde do Brasil.

Observou-se uma diminuição na produção de conhecimento no que tange a cogestão e saúde mental, principalmente nos últimos anos, levando assim, a pensar o que tem feito os pesquisadores a se afastar desse tema de fundamental importância quando pensado em saúde mental? Como considerar a autonomia do usuário da rede, se nossos saberes e práticas compartilhados estão limitados apenas ao compartilhamento entre os profissionais em si? Reconhecer a autonomia do usuário está também em convidar ele a se colocar nessa posição de gestor da sua própria saúde, algo muitas vezes até discutido e colocado na fala dos profissionais, mas que poucas vezes é encontrado nas ações de saúde.

No tangente ao cenário atual de pandemia, até o presente momento, nada se foi encontrado sobre cogestão nos espaços de saúde. Sendo de fundamental importância que seja avaliado essa questão, já que os espaços de maior cogestão nos dispositivos da rede se encontravam nos grupos organizados dentro dos dispositivos de saúde, que deixaram de ser realizados devido os riscos de contágio da Covid-19.

Desse modo, conclui-se que ainda é necessário que haja um esforço dos profissionais de saúde e dos gestores em promover a cogestão de forma plena, passando a considerar os usuários como peça fundamental para que ela seja executada, visando a construção de espaço que fomentem discussões sobre o cuidado em saúde mental de modo compartilhado por todos os atores sociais.

Sendo assim, este trabalho visa instigar e potencializar novas discussões sobre essa temática, de modo a repercutir em produções inovadoras que fomentem argumentações e construções que reconheçam sobre o trabalho em conjunto dos gestores, profissionais e usuários, como peças elementares e intrínsecas para a cogestão. 


\section{Referências}

Amarante, P. (1996). Loucos pela vida: a trajetória da reforma psiquiátrica no Brasil. Rio de Janeiro: Fiocruz.

Bardin, L. (2011). Análise de conteúdo. São Paulo: Edições 70.

Botelho, L. L. R., Cunha, C. C. A. \& Macedo, M. (2011). O método da revisão integrativa nos estudos organizacionais. Gestão e Sociedade. 5(11), 12136. https://doi.org/10.21171/ges.v5i11.1220.

Calderon, D. B. de L., \& Verdi, M. I. M. (2014). Cogestão e processo de intervenção de apoiadores da política nacional de humanização (PNH). Interface: Communication, Health, Education, 18, 859-870. https://doi.org/10.1590/1807-57622013.0960

Campos, G. W. de S. (2010). Cogestão e neoartesanato: elementos conceituais para repensar o trabalho em saúde combinando responsabilidade e autonomia. Ciencia e Saude Coletiva, 15(5), 2337-2344. https://doi.org/10.1590/s1413-81232010000500009

Costa, D. F. C. da, Flores, G. C., \& Andreeti, T. O. (2015). Educação permanente e cogestão: experiência de um grupo gestor em saúde. Estudos Interdisciplinares Em Psicologia, 6(1), 119. https://doi.org/10.5433/2236- 6407.2015v6n1p119

Cunha, J. P. P., Cunha, R.E. (1998) Sistema Único de Saúde - SUS: princípios. In: Campos, F.E., Oliveira Júnior, M., Tonon, L.M. Cadernos de saúde: planejamento e gestão em saúde. Belo Horiozonte: COOPMED, 11-26.

Silva, A. M., Sá, M. de C., \& Miranda, L. (2015). Entre "feudos" e cogestão: Paradoxos da autonomia em uma experiência de democratização da gestão no âmbito hospitalar. Ciencia e Saude Coletiva, 20(10), 3063-3072. https://doi.org/10.1590/1413-812320152010.02422015

Castro, C. P., de Oliveira, M. M., \& Campos, G. W. de S. (2016). Apoio Matricial no SUS Campinas: Análise da consolidação de uma prática interprofissional na rede de saúde. Ciencia e Saude Coletiva, 21(5), 1625-1636. https://doi.org/10.1590/1413-81232015215.19302015

Doricci, G. C., \& Guanaes-Lorenzi, C. (2020). Aspectos contextuais na construção da cogestão em Unidades Básicas de Saúde. Saúde Em Debate, 44(127), 1053-1065. https://doi.org/10.1590/0103-1104202012708

EndNote Web (2021). [place unknown]; https://access.clarivate.com/login?app=endnote

Escorel, S. (2015). Sergio Arouca: Democracia e Reforma Sanitária. In: Hochman G, Lima NT. Médicos Intérpretes do Brasil. São Paulo: Editora Hucitec.

Guizardi, F. L., \& Cavalcanti, F. de O. L. (2010). O conceito de cogestão em saúde: Reflexões sobre a produção de democracia institucional. Physis, 20(4), 1245-1265. https://doi.org/10.1590/S0103 73312010000400010

Mendes, K. D. S., Silveira, R. C. de C. P., \& Galvão, C. M. (2008). Revisão integrativa: método de pesquisa para a incorporação de evidências na saúde e na enfermagem. Texto \& Contexto - Enfermagem, 17(4), 758 764. https://doi.org/10.1590/s0104-07072008000400018

Ministério da Saúde do Brasil (2013). Política Nacional de Humanização. Brasília, D. F.: Humaniza SUS.

Paim, J., Travassos, C., Almeida, C., Bahia, L., \& MacInko, J. (2011). The Brazilian health system: History, advances, and challenges. The Lancet, 377(9779), 1778-1797. https://doi.org/10.1016/S0140 6736(11)60054-8

Pereira, N., \& Campos, G. W. de S. (2014). O apoio institucional no sistema Único de Saúde (SUS): Os dilemas da integração interfederativa e da cogestão. Interface: Communication, Health, Education, 18, 895-908. https://doi.org/10.1590/1807-57622013.0424

Peters M. D. J., Godfrey C. M, Khalil H., McInerney P., Parker D. \& Soares C.B. (2015) Guidance for conducting systematic scoping reviews. Int J Evid Based Healthc [Internet]. (3): 141-6.

Pinto, H. A., Sousa, A., Florêncio, A. R. (2012). O programa nacional de melhoria do acesso e da qualidade da atenção básica: reflexões sobre o seu desenho e processo de implantação. R. Eletrônica de Comunicação, Informação e Inovação em Saúde, 6(2), 1-19.

Sampaio, J. J. C., Guimarães, J. M. X., Carneiro, C., \& Garcia Filho, C. (2011). O trabalho em serviços de saúde mental no contexto da reforma psiquiátrica: um desafio técnico, político e ético. Ciência \& Saúde Coletiva, 16(12), 4685-4694. https://doi.org/10.1590/s1413-81232011001300017

Tenório, F. (2002). A reforma psiquiátrica brasileira, da década de 1980 aos dias atuais: história e conceitos. História, Ciências, Saúde-Manguinhos, 9(1), 2559. https://doi.org/10.1590/s0104-59702002000100003 